\title{
Knowledge and Practice of Fundoscopy among Medical Doctors in Port Harcourt, Nigeria
}

\author{
A. A. Onua*, B. Fiebai \\ Department of Surgery, University of Port Harcourt, Port Harcourt, Nigeria \\ Email: *onuadr@gmail.com
}

Received 28 June 2016; accepted 16 August 2016; published 19 August 2016

Copyright (C) 2016 by authors and Scientific Research Publishing Inc.

This work is licensed under the Creative Commons Attribution International License (CC BY). http://creativecommons.org/licenses/by/4.0/

(c) (i) Open Access

\section{Abstract}

Background: Many clinical entities manifest early characteristic changes in the fundus of the eye. The value of fundoscopy cannot be overemphasized and every medical doctor is expected to be able to use the ophthalmoscope to detect common pathological changes. However, more often than not fundoscopy is seen as an exclusive specialized skill of the ophthalmologist. Aim: The aim of this study was to evaluate knowledge and practice of fundoscopy among the physicians present at the Ordinary General Meeting of the Nigerian Medical Association (Rivers State branch) held in Port Harcourt on $3^{\text {th }}$ June 2014. Methods: A self administered questionnaire about their knowledge and practice of fundoscopy was administered to 125 medical doctors attending the Ordinary General Meeting of the Nigerian Medical Association (Rivers State branch) held in Port Harcourt on $30^{\text {th }}$ June 2014. Questions asked tested the Knowledge and Practice of the physicians on matters related to fundoscopy. Participants' knowledge and practice were graded as Good for scores of $75 \%$ and above, Fair for $50 \%$ - 74\% score and Poor for scores less than $50 \%$. Respondents' demographic data, responses and corresponding scores were entered into computer software-Scientific Package for Social Sciences (SPSS) version 20 and subsequently analyzed. Results: The study participants were 125 physicians; 86 males and 39 females (M:F = 2.2:1). Twenty-eight percent of the study participants had good knowledge of fundoscopy while only $15 \%$ had good practice. Seventy eight physicians representing $62.4 \%$ of the participants could correctly refer patients with the need for fundoscopy to an ophthalmologist, whereas $11(8.8 \%)$ worked in facilities without basic instrument for fundoscopy (ophthalmoscope). Conclusion: Our study demonstrates that knowledge and practice of fundoscopy among medical practitioners in Port Harcourt is poor and far from ideal. Therefore, refresher courses emphasizing the acquisition of the skill in fundoscopy and the provision of ophthalmoscopes in our General Practitioners' clinics are necessary.

\footnotetext{
"Corresponding author.
} 


\section{Keywords}

\section{Practice, Fundoscopy, Physicians}

\section{Introduction}

Ophthalmic fundoscopy assesses the optic disc, the vessels, the retinal background, the macula and the retina periphery with the purpose of arriving at a conclusion that the eye is normal or otherwise. It is of diagnostic, therapeutic and follow-up significance. Detailed fundus examination is an integral part of comprehensive and optimum clinical care in neurological examination and ophthalmic refractive patients. The fundus of the eye may reveal changes related to common diseases such as hypertension and diabetes mellitus [1] [2]. These changes can be observed in the pre-clinical stage of the disease, thus, of a great value in early disease detection. In a large range of patients-which are suggestive of hypertensive retinopathy, sclerotic changes are primarily seen in the choroidal vessels and later exudation and flame shaped haemorrhages give the picture of hypertensive retinopathy [1]. In addition to this, patients who have had diabetes mellitus for 10 years or more are likely to present initially to the general practitioner with features of diabetic retinopathy ranging from the non-proliferative type (retinal microaneurysms, exudates, haemorrhages) to the proliferative type (neovascularization, vitreous haemorrhages or retinal detachment) [3]. The General Practitioner (GP) should be able to recognise pathological changes in the fundus concerning the aforementioned diseases and if he finds something suspicious, he should always refer the patient to an ophthalmologist for a more specific and detailed ophthalmological examination, but not as an "emergency" case [4].

It is worthy to mention that "unnecessary" referrals of fundoscopy could be reduced if all the physicians especially the general practitioners are able to carry out the procedure. Usually GPs, paediatricians and doctors of internal medicine refer patients to ophthalmologists to undergo fundoscopy either as an "emergency" case or in the context of a detailed systemic clinical examination [4]. In "emergency" cases, the most frequent question is whether optic disc edema exists. Papilloedema is optic disc swelling secondary to increased intracranial pressure and its presence should raise the suspicion of serious intracranial pathology; i.e. tumors, venous sinus thrombosis, subarachnoid haemorrage, CNS infection, haematoma or idiopathic intracranial hypertension. In these cases, ophthalmoscopy is a very important diagnostic tool in GP's hands. Fundoscopy's value is also significant in cases of head trauma, as it can reveal intracranial haemorrhages or causes of low vision (intravitreal haemorrhage or retinal detachment). The GP should refer and co-manage the patient with an ophthalmologist and a neurosurgeon.

Another special finding in fundoscopy is retinal or vitreous detachment, something difficult for a GP to diagnose with certainty. In these cases, the GP should be suspicious; from the history of the patient and from the presenting signs and symptoms, such as photopsias or floaters. If the GP is not sure about the diagnosis of retinal breaks or retinal detachment, it is better to refer the patient to an ophthalmologist, because this is an ocular emergency and may cause loss of vision, when treatment is not appropriate and prompt.

\section{Materials and Method}

This study was conducted among medical doctors in Rivers states attending the Ordinary General Meeting of the Nigerian Medical Association (Rivers State branch) held in Port Harcourt on $30^{\text {th }}$ June 2014. Ethical approval for the study was obtained from the Research and Ethics Committee of the University of Port Harcourt Teaching Hospital, Port Harcourt.

Self-administered questionnaire was the research instrument. One hundred and twenty-five respondents who verbally consented were recruited for the study. Questions asked tested the Knowledge (13) and Practice (7) of the physicians on matters relating to fundoscopy. Participants' knowledge were graded as Good for scores of $75 \%$ and above, Fair for 50\% - 74\% score and Poor for scores less than 50\%. Respondents' demographic data, responses and corresponding scores were entered into computer soft ware-Scientific Package for Social Sciences (SPSS) version 20 and subsequently analyzed. Results were presented in tables and charts. Chi square tests were performed between categorical variables to determine their level of statistical significance. A p-value of 0.05 was accepted as significant. 


\section{Results}

A total of 125 physicians participated in this study. Eighty six were males and 39 females (M:F = 2.2:1). Maximum age of participants was 61 and minimum 25. The mean age was $37.9 \pm 8.4$ years. There was no statistical difference in the age distribution of the participants $(p=0.604)$ [Table 1 ].

The duration of practice among the physicians in this study is shown in Table 2 . The mean time of medical practice experience of the participants was $11.5 \pm 8.7$ years. The highest number of years of experience was 37 years while the least was one year. Over $50 \%$ of the physicians had less than 11 years of working experience.

Over $75 \%$ of the physicians were general practitioners. Only $23 \%$ were specialists in various areas of medical practice [Table 3].

Thirty five physicians (28\%) had good knowledge of fundoscopy, while knowledge of 43 participants (34.4\%) was fair and 47 (37.6\%) had poor knowledge of fundoscopy [Figure 1].

The level of practice of fundoscopy among 19 (15.2\%) participating physicians in this study was good, 20 (16\%) had fair practice while 86 (68.8\%) had poor practice level [Figure 2].

Table 1. Age and sex distribution of the study population.

\begin{tabular}{|c|c|c|c|}
\hline \multirow{2}{*}{$\begin{array}{l}\text { Age Group } \\
\text { (Years) }\end{array}$} & \multicolumn{2}{|c|}{ Sex } & \multirow{2}{*}{ Total (\%) } \\
\hline & Male (\%) & Female (\%) & \\
\hline $25-29$ & $11(8.8)$ & $7(5.6)$ & 18 (14.4) \\
\hline $30-34$ & 21 (16.8) & $14(11.2)$ & 35 (28.0) \\
\hline $35-39$ & 14 (11.2) & $6(4.8)$ & $20(16.0)$ \\
\hline $40-44$ & 19 (15.2) & $7(5.6)$ & 26 (20.6) \\
\hline $45-49$ & $11(8.8)$ & $1(0.8)$ & $12(9.6)$ \\
\hline $50-54$ & $6(4.8)$ & $3(2.4)$ & $9(7.2)$ \\
\hline $55-59$ & $3(2.4)$ & $1(0.8)$ & $4(3.2)$ \\
\hline 60 \& Above & $1(0.8)$ & $0(0)$ & $1(0.8)$ \\
\hline Total & 86 (68.8) & 39 (31.2) & 125 (100) \\
\hline
\end{tabular}

Table 2. Duration of practice among the physicians in the study.

\begin{tabular}{ccc}
\hline Duration of Practice Yrs & Number of Physicians & Percentage \\
\hline$\leq 5$ & 37 & 29.6 \\
$6-10$ & 32 & 25.6 \\
$11-15$ & 22 & 17.6 \\
$16-20$ & 18 & 14.4 \\
$21-25$ & 6 & 4.8 \\
$26-30$ & 5 & 4.0 \\
$31-35$ & 4 & 3.2 \\
36 \& Above & 1 & 0.8 \\
Total & 125 & 100 \\
& Pearson Chi Square $=1.875 ;$ p-value $=0.966$ & \\
\hline
\end{tabular}


Table 3. Distribution of physicians according to specialization.

\begin{tabular}{ccc}
\hline Specialization & Number of Physicians & Percentage \\
\hline Specialists-in-Training & 2 & 1.6 \\
Non-specialists (General Practitioners) & 94 & 75.2 \\
Specialists & 29 & 23.2 \\
Total & 125 & 100 \\
\hline
\end{tabular}

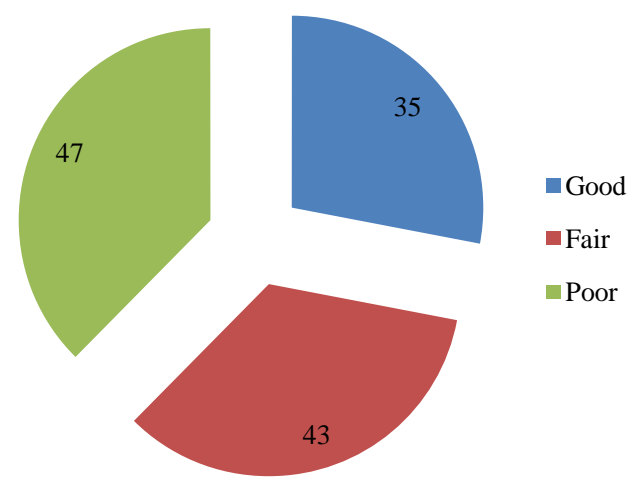

Figure 1. Assessment of knowledge of fundoscopy among physicians in the study.

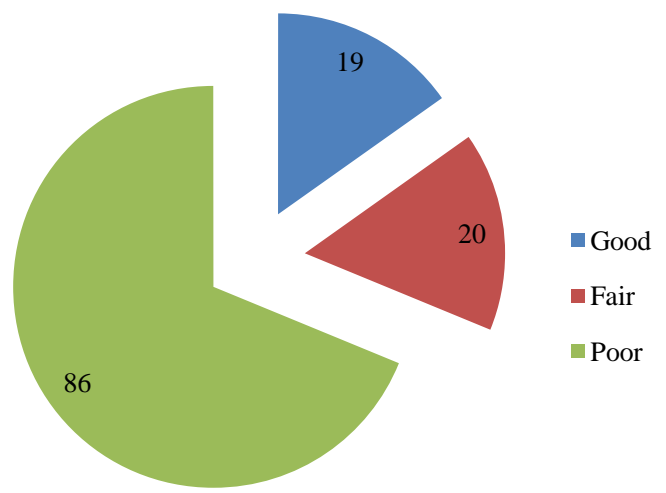

Figure 2. Assessment of the level of practice of fundoscopy among physicians in the study.

\section{Discussion}

Dilated fundus examination is an integral part of optimum clinical care in neurological examination and ophthalmic refractive patients, and shared preoperative assessment by a vitreo-retinal specialist is advisable in those with predisposing retinal pathology. Despite the fact that fundoscopy is a key element of full neurological examination, experience in medical evaluation of patients is that fundoscopy is rarely, if ever, performed [5]-[7]. The American Academy of Ophthalmology (AAO) recommends that the first fundus examination (FE) in patients with type 1 diabetes should be performed 5 years after diagnosis of the disorder [5].

This study reveals that fundoscopy is an under-performed examination in medical evaluation of patients among medical practitioners in Port Harcourt, Nigeria. This finding collaborates with the study of Khandekar et $a l$. in the North Sharqiya region of Oman where out of 40 randomly selected physicians studied only $58 \%$ had knowledge about method of fundus examination and $40 \%$ had poor practice of fundoscopy [5]. Although the sample size of the Oman study was small, the common phenomenon in the two studies is that practicing physicians have inadequate knowledge and poor practice of fundoscopy. This study is also in line with the findings of 
Rajiv Raman et al. [8], Schulz et al. [9] on the poor knowledge and practices of fundoscopy among medical practitioners.

There is therefore need to develop different methods of learning to help trainees acquire basic clinical skills, and medical practitioners to maintain and utilize current skill of fundoscopy. Serving medical doctors may also benefit from continuous medical education aimed at updating their knowledge in fundoscopy.

The place of ophthalmology in the undergraduate medical curriculum is slowly fading - with certainty, and yet without objection [10]. Over the past 30 years, the duration of the ophthalmology placement has dwindled in the United States, the United Kingdom, and elsewhere [10]-[12]. The inescapable truth is that without renewed activism from ophthalmologists interested in the education of tomorrow's doctors, the ophthalmology clerkship-exposed by poor representation from ophthalmologists on medical school committees—may soon disappear entirely [13] [14].

In this study, $47 \%$ of the study population had poor and inadequate knowledge of ophthalmology. The likely outcome is a generation of clinicians who lack confidence and competence in basic ophthalmic examination. This study reveals the need for training medical doctors and especially General Practitioners on the use of direct ophthalmoscope.

In this study, the main barrier to fundoscopy was lack of essential instrument-ophthalmoscope in some of our facilities. McCarty [10] reported lack of dilating drops in the practice, lack of confidence in detecting changes, concern about time taken and fear of precipitating angle-closure glaucoma with their patients as some of the barriers expressed by GPs in carrying out ophthalmoscopy on their patients. These need to be addressed through adequate provision of essential instrument in our consulting rooms and through more education and practice.

\section{Conclusion}

Our study demonstrates that knowledge and practice of fundoscopy among medical practitioners in Port Harcourt is poor and far from ideal. Therefore, refresher courses emphasizing the acquisition of the skill in fundoscopy and the provision of ophthalmoscopes in our General Practitioners' clinics are necessary.

\section{References}

[1] Chatziralli, I.P., Kanonidou, E.D., Keryttopoulos, P., Dimitriadis, P. and Papazisis, L.E. (2012) The Value of Fundoscopy in General Practice. The Open Ophthalmology Journal, 6, 4-5. http://dx.doi.org/10.2174/1874364101206010004

[2] Ayanniyi, A.A., Monsudi, K.F., Balarabe, A.H. and Isa, A.F. (2014) Do Medical Practitioners Perform Eye Examination as a Component of Managing Diabetic Patients? Saudi Journal for Health Sciences, 3, 32-36. http://dx.doi.org/10.4103/2278-0521.130203

[3] Dalay, S., Umar, F. and Saeed, S. (2013) Fundoscopy: A Reflection upon Medical Training? The Clinical Teacher, 10, 103-106. http://dx.doi.org/10.1111/j.1743-498X.2012.00630.x

[4] Gill, J.M., Cole, D.M., Lebowitz, H.M. and Diamond, J.J. (2004) Accuracy of Screening for Diabetic Retinopathy by Family Physicians. The Annals of Family Medicine, 2, 218-220. http://dx.doi.org/10.1370/afm.67

[5] Khandekar, R., Shah, S. and Al Lawatti, J. (2008) Retinal Examination of Diabetic Patients: Knowledge, Attitudes and Practices of Physicians in Oman. Eastern Mediterranean Health Journal, 14, 850-857.

[6] Vashist, P., Singh, S., Gupta, N. and Saxena, R. (2011) Role of Early Screening for Diabetic Retinopathy in Patients with Diabetes Mellitus: An Overview. Indian Journal of Community Medicine, 36, 247-252. http://dx.doi.org/10.4103/0970-0218.91324

[7] Bloomgarden, Z.T. (2007) Screening for and Managing Diabetic Retinopathy: Current Approaches. American Journal of Health-System Pharmacy, 64, 8-14. http://dx.doi.org/10.2146/ajhp070331

[8] Raman, R., Paul, P.G., Padmajakumari, R. and Sharma, T. (2006) Knowledge and Attitude of General Practitioners towards Diabetic Retinopathy Practice in South India. Community Eye Health, 19, 13-14.

[9] Schulz, C. and Hodgkins, P. (2014) Factors Associated with Confidence in Fundoscopy. The Clinical Teacher, 11, 431-435. http://dx.doi.org/10.1111/tct.12171

[10] McCarty (1987) Management of Diabetic Retinopathy by General Practitioners in Victoria. Clinical \& Experimental Ophthalmology, 29, 12-16. http://dx.doi.org/10.1046/j.1442-9071.2001.00359.x

[11] Khandekar, R. (2012) Screening and Public Health Strategies for Diabetic Retinopathy in the Eastern Mediterranean Region. Middle East African Journal of Ophthalmology, 19, 178-184. http://dx.doi.org/10.4103/0974-9233.95245

[12] Mohamed, Q., Gillies, M.C. and Wong, T.Y. (2007) Management of Diabetic Retinopathy: A Systematic Review. JAMA, 
298, 902-916. http://dx.doi.org/10.1001/jama.298.8.902

[13] Yusuf, I.H., Salmon, J.F. and Patel, C.K. (2015) Direct Ophthalmoscopy Should Be Taught to Undergraduate Medical Students-Yes. Eye, 29, 987-989. http://dx.doi.org/10.1038/eye.2015.90

[14] Alsharif, A.I. and Al-Khaldi, Y.M. (2001) Attitude, Practice and Needs for Continuing Medical Education among Primary Health Care Doctors in Asir Region. Journal of Family and Community Medicine, 8, 37-44.

\section{Submit or recommend next manuscript to SCIRP and we will provide best service for you:}

Accepting pre-submission inquiries through Email, Facebook, LinkedIn, Twitter, etc.

A wide selection of journals (inclusive of 9 subjects, more than 200 journals)

Providing 24-hour high-quality service

User-friendly online submission system

Fair and swift peer-review system

Efficient typesetting and proofreading procedure

Display of the result of downloads and visits, as well as the number of cited articles

Maximum dissemination of your research work

Submit your manuscript at: http://papersubmission.scirp.org/ 